\title{
Research on Inequality in Education of Girls in Poverty-stricken Areas
}

\author{
Tianyue $\mathrm{Wu}$ \\ Shenzhen Middle School, Shenzhen 518001, China. \\ christinawutianyue@gmail.com
}

Keywords: Educational gender inequality, education of girls in impoverished areas, dropping out of school.

\begin{abstract}
The problem of educational inequality is one of the major issues that restrict the development of education, and it is also a social issue. Education inequality among girls in impoverished areas is one of the main manifestations of education inequality. Gils dropping out of school in remote and impoverished areas have not been solved effectively so far. In addition to inadequate rural education funds, inadequate policies and regulations, and this problem is inseparable from the society, history, family, and school. Therefore, it is urgent to solve the problem of girls dropping out of school in impoverished areas. Based on the above factors, the researcher tried to make the following suggestions. The most essential solution is to improve the economy. Second, improve laws and regulations to protect the rights and interests of girls' education. Third, take steps to make people change traditional gender stereotype. Fourth, implementing compulsory education thoroughly is the fundamental solution to the problem of girls' difficulties in school. Fifth, make the study content more suitable for the development of rural students. Last but not the least, teachers should pay more attention on the girls.
\end{abstract}

\section{Introduction}

With the continuous deepening of China's education reform, the issue of education inequality has become more prominent as well. Obvious regional disparities, irrational allocation of educational resources, discrimination in private education, and difficulties in rural education and so forth are among the obstacles that constrain China's education development and the creation of harmonious society. In rural basic education, the issue of unfair education caused by gender inequality is one of the major problems.

\section{Educational Gender Inequality in Poor Areas}

Educational equality is that every child can receive education and enjoy the same treatment, and will not be unfairly treated because of family, background, gender and other factors. Education Law of the People's Republic of China makes it clear that "Citizens of the People's Republic of China shall have the right and obligation to receive education. All citizens, regardless of ethnic group, race, sex, occupation, property status or religious belief, shall enjoy equal opportunities for education according to law. "But what is true education equity, and how it is embodied in our lives, cannot be clearly illustrated through abstract legal provisions.

Dealing with the problem of ubiquitous education inequality, the most attention need to be paid on people with the most unequal treatment, that is, the education of girls in poverty-stricken areas. According to data from NBSPRC, among illiterate population above 15 years old (village), the number of female illiterates was 2.71 times that of male illiterate population; among people who has never been to school, there are approximately 32 million female and 13 million male.

By 2010, the coverage rate of China's nine-year compulsory education reached 85\%. However, 60 to $70 \%$ of the remaining $15 \%$ uncovered people were women, and about 60 percent of the 60 to 70 percent of uneducated women are from poor villages. All the data points to a common fact that education for men and women in poor areas is unfair. Why is the problem still severe under the situation that China has already experienced a large increase in economy and education investment? 


\subsection{Teachers' Attitudes and Behaviors.}

Teachers' attitudes and behaviors have an important influence on the formation of students' thinking and behavioral habits, especially among younger students. Under the influence of unequal gender culture, most teachers accept and agree with the education process and provide differentiated education for male and female students. In classroom teaching, teachers tend to ask boys open ended question, and ask girls questions about memory. Girls should keep quiet and well-behaved and be more obedient to the teachers' instructions. Boys, on the other hand, can be naughty and perform more positively and creatively in various activities. Are these teachers' "should do" correct? Who give definitions to these "should do"?

The well-known Rosenthal effect of the psychology circle, namely, the interpersonal expectation effect, can interpret that teacher's expectation of children of different genders can bring them different future development. For example, boys are expected to have high expectations, and they will be given more attention, both intentionally or unintentionally, thus making greater progress in learning or other aspects. Even if many teachers do not admit that they have the concept of inequality between men and women, they will instill such thoughts in the subtleties. For example, teachers would say, "Although girls can get higher grades now, but after a few years, it will be the time for boys to develop and they will catch up with girls." The influence of these words cannot be ignored. Their attitude has given students a sense of gender stereotype.

Spencer, a British sociologist, points out that teachers often fail to realize that their unfair treatment between men and women has affected in-class activities. "Teachers actually interact with boys more than twice of girls; and when teachers interact with girls more than one-third of the entire interaction time, the interaction between teachers and boys in the class has already exceeded half." (Yang Baozhong, 2016) Many studies and experiences have shown that in the classroom, especially in the classrooms in poor areas, teachers' reply to students is different. Most of the responses to the boys' speeches were encouraging and supportive, while the responses to the girls only had relatively vague feedback of "good" and "yes." This behavior will result in the situation that girls do not get a deeper understanding of the same issue.

For most teachers, using different scales to measure will bring different results. Different evaluations and feedbacks have brought different requirements, which have brought different ways of education.

\subsection{Gender Inequality in Textbooks.}

There are serious gender inequalities in China's primary and secondary school textbooks, according to Zhu Xiaobin's primary school full-time five-year Chinese textbook (People's Education Edition, the 2nd edition, 1988), A complete set of six year full-time Chinese textbooks for primary schools jointly compiled and published by four provinces and cities of Shanghai, Zhejiang, Beijing and Tianjin (edition 3 of 1988, edition 4 of provinces and cities), and a full set of six year full-time Chinese textbooks for primary schools (edition 3, 1988, edition 4) jointly compiled and published by four provinces and cities of Shanghai, Zhejiang, Beijing and Tianjin. Among them, the number of male leading character in the story is more the female protagonist, and the people education edition reaches $77.7 \%$, the four provinces and cities edition account for $69.0 \%$, and the Zhejiang edition is 53.3. $\%$, while the proportion of female protagonists was only $13.2 \%, 14.9 \%$ and $21.7 \%$ respectively. The illustrations of the story are also more male and less female. There is a serious gender inequality in the primary and secondary school textbooks in China. In terms of ability, the male image is often very knowledgeable, superb, and lofty, while the female image is ignorant. In the scene where both male and female images appear at the same time, the female's ability is even lower, and she needs the help, solution, correction and summary of the male character. In terms of character, textbooks focus many of the outstanding human characters such as hard-working, brave, honest, kind and solidarity on men. Some of the human characters are dark and greedy, narrow-minded, and fierce are represented by female character. [3]. 


\section{Reasons for Education on Gender Inequality}

As what has been shown in Table 2, in the investigation of impoverished areas in the west, Wang Qiang of Nanjing Normal University conducted a sample analysis of the reason why girls aged 7 to 15 years old from Sanxiang, Guizhou Province, were not enrolled in or dropped out of school. According to the influence factors in the chart, we can divide it into three parts, which are social factors, historical factors and family factors. In the analysis, the author found that these factors are in fact a vicious circle, which intensifies the unfairness of female students' education. The backward areas will cause backward education, and the backwardness of education will lead to the overall backwardness of the local politics, economy, and culture.

Table 1. Reasons for girls not attending school or dropping out of school at 7-15 years old, Sanxiang, Qijiang County, Guizhou Province, 1995

\begin{tabular}{|c|c|c|}
\hline Factors & Number of people & (Proportions) (\%) \\
\hline Family economic difficulties & 1016 & 76.7 \\
\hline The family lacks labor & 136 & 10.3 \\
\hline Taking care of girls and ignoring the education of girls & 102 & 7.7 \\
\hline Far from school and difficult to go to school & 38 & 2.9 \\
\hline The school lacks female teachers & 20 & 1.5 \\
\hline Disability & 13 & 0.9 \\
\hline Total & 1325 & 100.0 \\
\hline
\end{tabular}

\subsection{Social Factors.}

\subsubsection{Less Investment in Education.}

According to the statistics of the National Bureau of Statistics of China, the GDP for 2017 was 8271.22 billion Yuan, but the total investment in education in 2017 was only 4,255.7 billion Yuan, accounting for $5.14 \%$. Of the education funds that account for $5.14 \%$ of GDP each year, most of them are invested in higher education. In the few remaining education funds, the gap between the investment in urban and western rural areas is gradually widening. In the face of extremely harsh education funding, "cannot afford to go to school" is the direct reason why school-age children in poor families are dropping out of school. In UNESCO's Statistical Yearbook 1998, public education spending in developed countries is higher than that of developing countries. The higher the level of economic development, the greater the proportion of public education accounts for. In 1995, the average of public education expenditure in GDP was 5.2\% on the average in the world, 5.5\% in developed countries, $4.6 \%$ in developing countries, and 3.6\% in least developed countries. However, the rate in China is only 2.41\%, not only far lower than developed countries and the average is even lower than that of the least developed countries. Table 2 shows the ratio of education spending to GDP in the world in 2005. As can be seen from the table, China's investment in education in 2017 is less than that of the world 20 years ago, which is less than that of Western European countries10 years ago.

\subsubsection{Educational Regulations and Policies Are Incomplete.}

On the one hand, China's relevant education laws and regulations lack relevant punitive measures for educational violations. This kind of imperfectness provides a "vacuum area" for some educational violations, combined with traditional gender and cultural influences, resulting in the ratio of girls having difficulty in going to school in some areas. On the other hand, our country's education policy has always had the problem of "city orientation". Not only is there a preference for individual cities in the allocation of resources for education funds, but the national syllabus and teaching materials also have such problems. The enrollment quota for colleges and universities in all provinces has always been a black box that does not make public decisions. Apart from giving local candidates the highest admission rate, Beijing universities also take care of border areas and ethnic minority areas. In general, the Northern provinces are giving more attention compared to the southern provinces. Although Shanghai also takes care of frontier ethnic minority areas, it is clearly favoring the Yangtze 
River Delta and the provinces in the south of the Yangtze River. Students in Sichuan, Guangdong, and Henan are not given enough attention and care in the aspect of enrollment and education. This has led to the fact that students in many poverty-stricken areas think that study does not promise a better future, because of the pressure of study.

Table 2. Proportion of Domestic Education Bidding to Gross Domestic Product (GDP)

\begin{tabular}{|c|c|c|c|c|c|}
\hline & $\begin{array}{c}\text { Kindergarten } \\
\text { teacher-student } \\
\text { ratio (\%) }\end{array}$ & $\begin{array}{c}\text { Elementary } \\
\text { school } \\
\text { teacher-student } \\
\text { ratio (\%) }\end{array}$ & $\begin{array}{c}\text { Junior high } \\
\text { school } \\
\text { Teacher-student } \\
\text { ratio (\%) }\end{array}$ & $\begin{array}{c}\text { Teacher-pupil } \\
\text { ratio in tertiary } \\
\text { institutions (\%) }\end{array}$ & $\begin{array}{c}\text { The } \\
\text { pentage } \\
\text { of } \\
\text { educational } \\
\text { expenditure } \\
\text { to national } \\
\text { GDP (\%) }\end{array}$ \\
\hline France & 24.6 & 19.5 & 13.3 & 17.2 & 7.4 \\
\hline Ireland & 24.1 & 22.6 & 15.8 & 21.6 & 4.9 \\
\hline United & 19.1 & 21.3 & 15.6 & - & 5.4 \\
\hline Kingdom & 23.7 & 20.9 & 15.0 & 12.5 & 5.8 \\
\hline Germany & 20.0 & 20.0 & 18.6 & 18.7 & 5.3 \\
\hline Netherlands & 17.8 & 19.7 & 15.9 & 13.5 & 4.7 \\
\hline Japan & 19.4 & 18.0 & 15.1 & 17.6 & 5.7 \\
\hline Spain & 21.5 & 17.0 & 19.7 & 16.4 & 7.0 \\
\hline Canada & 21.9 & 16.9 & 16.1 & 14.1 & 6.7 \\
\hline United & 13.9 & 11.2 & 10.2 & 29.0 & 4.7 \\
\hline States & 13.1 & 11.2 & 11.0 & - & 7.1 \\
\hline Italy & Denmark & & & & \\
\hline
\end{tabular}

\subsection{3 "Exam-Oriented Education" Model.}

Although China has already begun to advocate "quality education" for a long time, the entire period of compulsory education was face-to-face and national quality education was implemented. However, due to the influence of traditional concepts such as "He who excels in learning can be an official" and the role of the baton in the senior high school entrance examination, in the basic education stage, especially in remote and impoverished areas, only the "scores" are of top priority, and people are more concerned about and stress examination ability and scores. A single theory of success in further studies has led to rural schoolgirls with unsatisfactory test scores experiencing learning-weariness and low interest in learning and initiative. Once the test scores are not good, students themselves lose their confidence in learning. Parents feel that there is no hope of further studies and no need to spend time and energy to study. As a result, rural girls leave school early and return to their homes.

\subsection{Historical Factors.}

The problem of unfair education among girls can be divided into two types. The first is the underdevelopment of their own education. The level of education in poor areas has been very underdeveloped since the founding of New China. The inertia of this underdevelopment has continued to this day. It directly affects the realization of education for girls. Followed by the emergence of looking up to men and down on women, ignoring the key to looking up to men and down on women in poor areas, the lack of women's dominant status and discourse power, women's participation in political power indirect influence on the education of girls, it is difficult for someone to speak for them. The direct manifestation of these historical inertial roles is to exclude girls in poverty from education; therefore, their experience is generally marrying people early, becoming a fertility machine, and getting a dowry to ease the family's poverty.

\subsection{School Factors.}

The number of schools in impoverished areas is generally less than expected, and it is generally built in villages with relatively good economic conditions, which led to the fact that children in 
impoverished villages need to walk a long way to go to school. The geographical conditions are unfavorable, which limits girls enrolling in school.

Except for geographical conditions, the single forms of educational methods, the bland study content in school may reduce girls' interest in studying, and this may discourage girls' interests to studying. Missing female teacher is also an important factor. The existence of female teachers actually encourages girls to go to school. They will worship and admire these female teachers, setting their own goals for the future, and thus have the motivation to learn. Furthermore, for schools providing boarding, girls may feel insecure, and the presence of female teachers will reduce their fear.

\subsection{Family Factors.}

On the one hand, families in poverty-stricken areas have a heavy financial burden and are unable to pay for their children's education. In the survey and analysis of Sanxiang, Qijiang County, Guizhou Province, the economic reason accounted for $76.7 \%$. In remote and impoverished areas, families have a heavy economic burden. In addition to the large number of children in many families, girls are often discriminated against in education. The second reason is that the feudal ideology has serious cancers. Many parents still believe in the idea that "A woman without talent is virtuous," and "a married daughter is like water thrown out." When they face boys or girls who go to school, most parents will give priority to allowing boys to go to school and deprive girls of their right to receive education. According to the survey data of the "Western China Social and Economic Development Detection and Research Project", 26.7\% of the female population in 12 western provinces and regions has never attended school; female illiterate population is $18.1 \%$ higher than male; among $7-14$-year-old children, the number of men attending school is $1.19 \%$ higher than that of women; the number of girls who do not attend school is $1.2 \%$ higher than that of boys; among the school-age population who are 15-25 years old, females who have never been at school and without staying in Grade Five in Primary School is $4.1 \%$ higher than men [4]. Third, parents' cultural quality is generally low. Studies have shown that parental education has an important influence on the education of children. Low levels of parental education, weak educational awareness, lack of attention to children's education, and lack of support for food and clothing are also the main reasons for the high dropout rate among rural girls. In particular, the mother's educational level directly affects and restricts the level of children's education. Relevant surveys have shown that families with high educational levels of mothers have high enrollment rates for girls; families with low educational levels have low enrolment rates and high turnover rates for girls.

\section{Conclusion and Future Study}

The problem of education inequality is still severe in China, and the most direct victims of this problem are those underprivileged girls in rural areas. This paper suggests the following actions that may improve the nowadays situation.

\subsection{Accelerate the Development of Rural Economy.}

The most essential solution is to improve the economy so that people can have a higher quality of life. Local governments and relevant departments should change the traditional rural economy according to actual local conditions, vigorously develop the economic industry, and only rural economic development can fundamentally improve the problem of insufficient rural education resources, improve the educational conditions of rural children, and improve education.

\subsection{Improve Laws and Regulations.}

Although China has issued education laws and clearly states that every citizen has the rights and obligation to receive education, the laws and policies still need to be amended since the awareness of gender equality is still deficient. First of all, the execution of existing laws and regulations should be strengthened to protect the girl's right to education, and severe punishment should be given to people who deny girls access to compulsory educations. Second, improve the corresponding laws and regulations so that they can adapt to the new issues happening in present days. In addition, it is necessary to establish a fair employment environment so that the girls' education input and output are 
in line with each other. Only by establishing a sound education laws and regulations system can we truly protect the rights and interests of girls' education.

\subsection{Change Traditional Gender Stereotype.}

In order to solve the problem of equitable education for girls in rural areas, traditional gender stereotypes that are not conducive to their education should be eliminated first. China's rural villages are deeply affected by the concept of traditional gender inequality. The thought of male superiority is deeply entrenched, especially among grandparents. The concept of gender equality should be promoted in rural areas through various channels, like broadcasting, television, and newspapers. To change the notion of traditional girls' uselessness, a special meeting also need to be convened among guardians who still hold the gender stereotype. Rural girls themselves should also establish a gender equality concept and increase their enthusiasm for learning, striving for a fair right to education for themselves.

\subsection{Full Implementation of Compulsory Education.}

In Article 4, the "Compulsory Education Law of the People's Republic of China" stipulates that every citizen is forced to receive compulsory education. In Article 10, the law states that "The state shall not charge tuition for students receiving compulsory education." While in article 17, "Implementing compulsory education Schools can collect miscellaneous fees." However, since the 1990s, when implementing, the tenth article has been diluted, and Article 17 has been expanded. This situation has caused the current compulsory education to shrink, and fee education is expanding. Thus, implementing compulsory education thoroughly is the fundamental solution to the problem of girls' difficulties in school.

\subsection{Revolution in Schools.}

The first thing needs to be changed it to make the study content more suitable for the development of rural students. Also, change the gender roles of existing textbooks and prepare textbooks with a clear concept of gender equality. The content of textbooks should reflect women's image and history, set examples for girls, enhance their self-confidence, and increase their expectations for themselves.

Furthermore, the influence of words and deeds of female teachers on girls is enormous. We should improve the quality of existing female teachers in rural area and set examples for girls. In addition, the gender structure of rural school leaders should be improved, which means more female should manage the school. For girls who lack of confidence, teachers should pay more attention on them and encourage them to actively participate in extra-curricular activities and help them build their confidence.

\section{Conclusion}

The problem of gender inequality in the education process not only exists in rural poverty-stricken areas, but also exists in cities and towns to varying degrees. To solve the problem of education for girls in rural areas, educators must face up to the gender differences that exist objectively. At the same time, efforts should be made to increase the level of gender equality in the education process so that students can receive equal opportunities for education and a balanced education resource to achieve education fairness. First, improve the cultural quality of parents, especially mothers, and optimize the family environment for girls' education. Second, the society is widely involved in optimizing the social environment for girls' education. Third, deepen rural education reforms and increase the attractiveness of schools for girls. Fourth, increase the subjective awareness of girls and overcome the psychological barriers to learning. Fifth, we must optimize the legal environment, improve the legal consciousness and legal quality of the entire society in safeguarding the legitimate rights and interests of girls, and effectively guarantee the right of girls to education. Solving gender inequalities in the education process is a long-term, large-scale, multi-dimensional, and multi-level systemic project. It not only needs to discard feudal ideology, change traditional concepts, but also requires full cooperation among governments at all levels, education, women's federations, schools, and families. 


\section{References}

[1]. Xia Zhengnong, Chen Chili. Ci Hai. Shanghai: Shanghai Lexicographical Press, 2009.

[2]. Information on: http://www.stats.gov.cn/tjsj/pcsj/rkpc/6rp/indexch.htm.

[3]. Zhu Xiaoping. The Socialization of Children's Gender Roles in China's Three Primary School Textbooks: A Comparison with a Reading Textbook in the United States. Educational Research, 1994(10):52-57.

[4]. China Science and Technology Promotion and Development Research Center. Western People's Life, Beijing: China Statistics Press, 2006.

[5]. Tina Keri. On the Equity of Girls Education in Western Poverty-stricken Areas 1. Journal of Southwest China Normal University (Humanities and Social Sciences), 2005(03):81-87.

[6]. Yang Taizhong, Shi Yangon. Inequality hidden under the fairness of girls' education--Discussion from the perspective of gender stereotypes. Journal of Shanxi Normal University (Social Science Edition), 2009, 36(S1):33-35.

[7]. Information on: http://tieba.baidu.com/p/1076033693.

[8]. The Education Law of the People's Republic of China.Law Press, 2016, p. 11-12.

[9]. UNESCO's Statistical Yearbook 1998.Educational Science Publishing House, 1999, p. 23-33.

[10]. Compulsory Education Law of the People's Republic of China. Law Press, 2015, p. 3-6. 